\title{
Angioedema of the small intestine in a 28-year-old woman
}

A 28-year-old obese women visited the emergency department with dyspnoea and umbilical abdominal pain intensifying for two weeks. The patient suffered from hereditary angioedema type (HAE) I. Three months earlier the woman delivered a child by caesarean section. The patient denied diarrhoea, constipation, or vomiting. A duty doctor administered the patient's plasma-derived C1-inhibitor intravenously. The dyspnoea withdrew, and abdominal pain was slightly relieved. The woman went home but returned after seven hours. The abdominal pain persisted. The patient was consulted by gynaecologists, who observed an excessive volume of fluid in the peritoneal cavity in vaginal and abdominal ultrasound. Besides that, no gynaecological abnormality was observed. White blood cell count was 17,000 per cubic millimetre and C-reactive protein (CRP) was 37 milligrams per cubic decimetre. Blood pressure, heart rate, and respiratory rate were within normal range. No physical signs of hydrothorax, obturation of respiratory tract, ascites, or bowel obstructions were presented. The patient received analgesics.

CT scan of the abdomen and pelvis revealed oedema of the small intestine and excessive fluid in the peritoneal cavity (Figure 1). The abdominal pain was diagnosed as angioedema of the small intestine. A second dose of C1-inhibitor was administered. After one hour the patient experienced relief of pain. The patient had never experienced abdominal attacks of angioedema before. The woman was observed for 48 hours and was discharged without complaints. On the day of discharge her white blood count was equal to 6.6 per cubic millimetre and CRP was 14 milligrams per cubic decimetre.

\section{Discussion}

Angioedema is a consequence of an episode of increased capillary permeability with extravasation of intravascular fluid and subsequent oedema. HAE of the small intestine appears as a mural and mucous thickening with fluid accumulation in the lumen but rarely with signs of ileus [1]. This case has several aspects worth detailed discussion. Firstly, abdominal attacks of hereditary angioedema tend to be self-limiting [2]

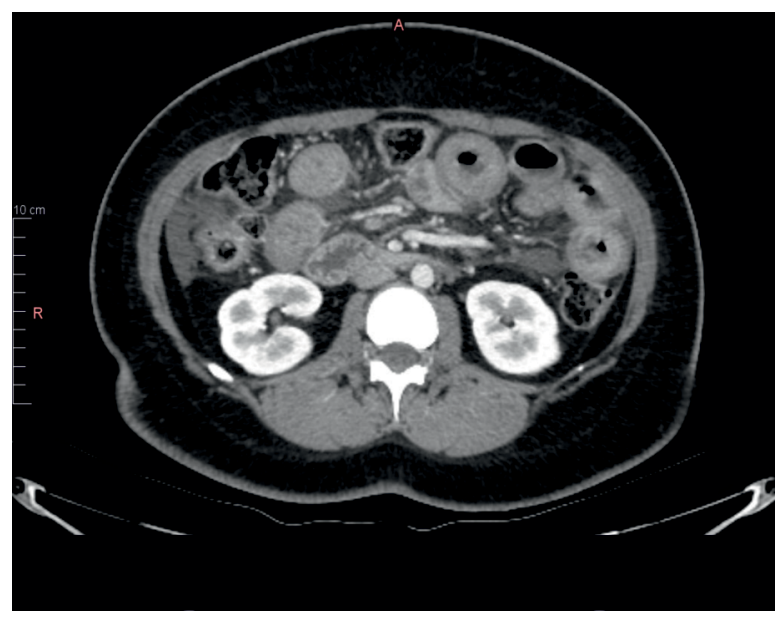

Figure 1. CT scan of the abdomen of a 28-year-old women with hereditary angioedema type 1. Arterial phase. See Supplementary files: Full CT scan of the abdomen of a 28-year-old women with hereditary angioedema type 1. Arterial phase

\section{Corresponding author:}

Mikołaj Kamiński, Department of General Surgery with subdivision of Urology, District Hospital in Oborniki, Poland, Szpitalna 2 Str., 64-600 Oborniki, Poland, e-mail: mikolaj.w.kaminski@gmail.com

Medical Research Journal 2019; Volume 4, Number 4, 225-226

10.5603/MRJ.a2019.0038

Copyright (C) 2019 Via Medica

ISSN 2451-2591 
and sensitive to $\mathrm{C} 1 \mathrm{q}$ inhibitor concentrate administration [3], while in the described case the attack lasted for two weeks and did not resolve 12 hours after the first dose. Secondly, the patient history did not reveal any potential triggers of the exacerbation. However, we hypothesise that the reconstitution of the female hormone levels after the postpartum period may lead to exacerbation of the disease [4]. The leukocytosis and elevated CRP serum level are uncommon in HAE attacks, but some patients present increased inflammatory markers regardless of different conditions $[5,6]$. After 48 hours the white blood count of the patient dropped to 6.6 per cubic millimetre and CRP to 14 milligrams per cubic decimetre. Therefore, we concluded that HAE attack was the reason for elevated leucocytes and CRP in the case. The patient experienced significant relief of abdominal pain and did not disclose any ailment. Moreover, we observed that the subsequent decrease of white blood count and CRP and other parameters were in the normal range. Therefore, we decided not to perform a control CT scan. Importantly, patient awares of the malady equipped with the specific drug can be diagnosed and treated even in a district hospital. Nevertheless, the care of this patient required careful diagnosis and the cooperation of different specialists.
Acknowledgements: None

Conflict of interest: None

\section{References}

1. De Backer Al, De Schepper AM, Vandevenne JE, et al. CT of angioedema of the small bowel. AJR Am J Roentgenol. 2001; 176(3): 649-652, doi: 10.2214/ajr.176.3.1760649, indexed in Pubmed: 11222198.

2. Bork K, Staubach P, Eckardt AJ, et al. Symptoms, course, and complications of abdominal attacks in hereditary angioedema due to C1 inhibitor deficiency. Am J Gastroenterol. 2006; 101(3): 619-627, doi: 10.1111/j.1572-0241.2006.00492.x, indexed in Pubmed: 16464219.

3. Zanichelli A, Azin GM, Cristina F, et al. Safety, effectiveness, and impact on quality of life of self-administration with plasma-derived nanofiltered C1 inhibitor (Berinert®) in patients with hereditary angioedema: the SABHA study. Orphanet J Rare Dis. 2018; 13(1): 51, doi: 10.1186/s13023-018-0797-3, indexed in Pubmed: 29631595

4. Czaller I, Visy B, Csuka D, et al. The natural history of hereditary angioedema and the impact of treatment with human $\mathrm{C} 1$-inhibitor concentrate during pregnancy: a long-term survey. Eur J Obstet Gynecol Reprod Biol. 2010; 152(1): 44-49, doi: 10.1016/j.ejogrb.2010.05.008, indexed in Pubmed: 20541309.

5. Henao MP, Kraschnewski JL, Kelbel T, et al. Diagnosis and screening of patients with hereditary angioedema in primary care. Ther Clin Risk Manag. 2016; 12: 701-711, doi: 10.2147/TCRM.S86293, indexed in Pubmed: 27194914

6. Calbo L, Quattrocchi P, Ferlazzo B. Abdominal attack of hereditary angioedema associated with marked leucocytosis. A case report. Ital J Gastroenterol. 1992; 24(8): 464-465, indexed in Pubmed: 1421450 . 